Document downloaded from:

http://hdl.handle.net/10251/140941

This paper must be cited as:

Desantes J.M.; García-Oliver, JM.; Xuan, T.; Vera-Tudela-Fajardo, WM. (2017). A study on tip penetration velocity and radial expansion of reacting diesel sprays with different fuels. Fuel. 207:323-335. https://doi.org/10.1016/j.fuel.2017.06.108

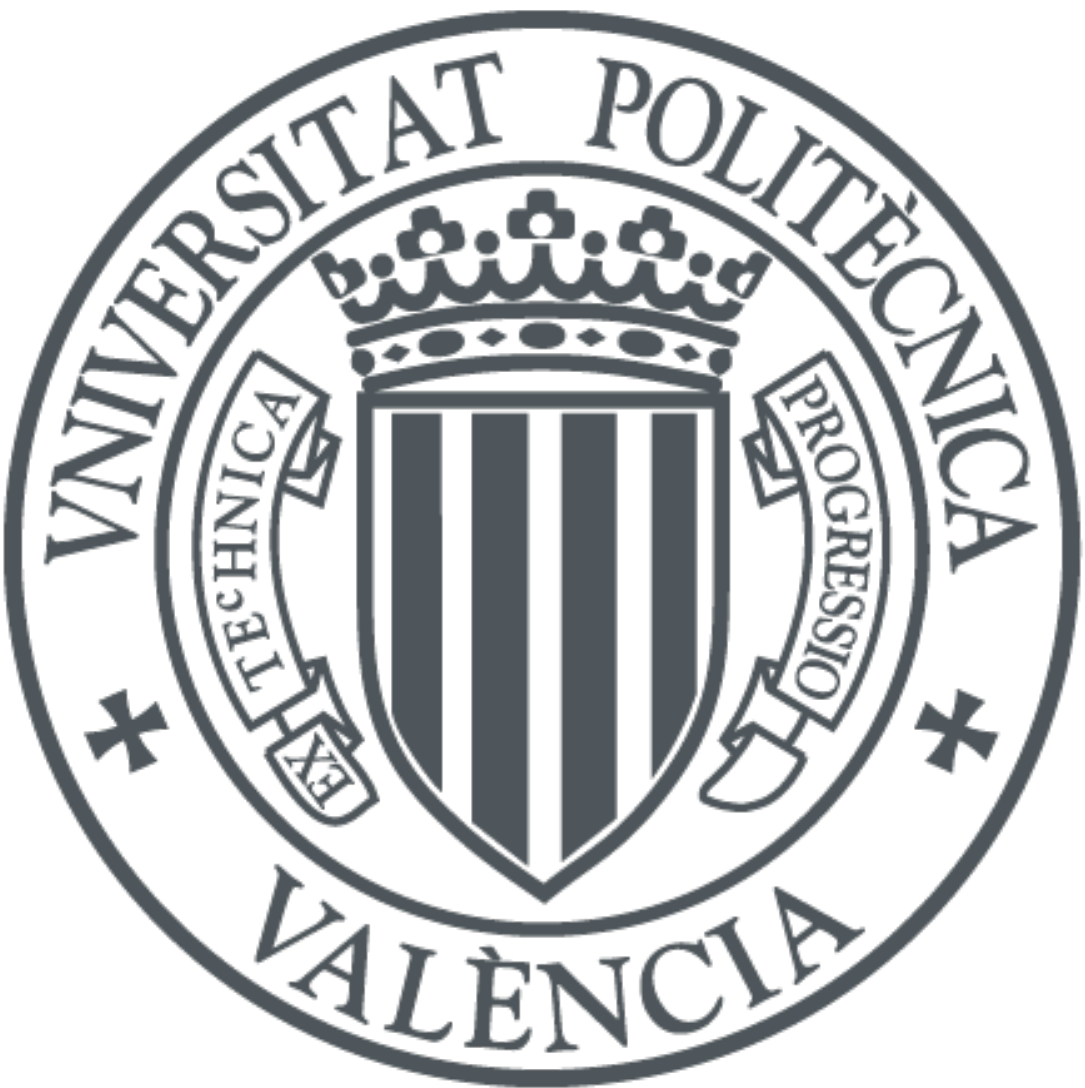

The final publication is available at

https://doi.org/10.1016/j.fuel.2017.06.108

Copyright Elsevier

Additional Information 


\title{
A study on tip penetration velocity and radial expansion of reacting diesel sprays with different fuels
}

\author{
J.M. Desantes ${ }^{a}$, J.M. García-Oliver ${ }^{a}$, T. Xuan ${ }^{a}$, W. Vera-Tudela ${ }^{b}$ \\ ${ }^{a}$ CMT Motores Térmicos - Universitat Politècnica de València, Valencia (Spain) \\ ${ }^{b}$ Laboratorium für Aerothermochemie und Verbrennungssysteme, Eidgenössische Technische Hochschule Zürich, \\ (Switzerland)
}

\section{ABSTRACT}

The reacting diesel spray structure was investigated using $n$-dodecane, $n$-heptane and one binary blend of Primary Reference Fuels ( $80 \%$ n-heptane and $20 \%$ iso-octane in mass) based on the existing database from previous experimental results from Schlieren imaging technique in a constant pressure combustion chamber. The spray tip velocity was derived from the derivative of tip penetration versus time. The operating conditions and the injector used (single axially-oriented hole, $89 \mathrm{~mm}$-diameter) were chosen following the guidelines of the Engine Combustion Network. A 1D spray model was also applied here to support the analysis of experimental results. Parametric variations of injection pressure, ambient temperature and oxygen concentration have been performed for each fuel. Analysis of radial expansion and reacting tip velocity was performed in terms of an average spray radial increase $(\overline{\Delta R})$ and a constant $(\mathrm{k})$ defining the tip penetration velocity. $\mathrm{k}$ values of reacting cases are always bigger than those from inert ones for both experimental and theoretical results. Based upon this parameter, quasi-steady tip penetration under the investigated conditions seems not to be affected by ambient temperature, oxygen content or fuel cetane number. Three cases with different fuels and similar ignition delay and lift-off length were further analyzed, which shows that the reactivity of the mixture has an effect on the transition timing from inert to reacting states, as well as on the initial penetration stages, but not on the quasi-steady phase. Apart from the similar tip velocity during quasisteady phase, the full transient evolution of the tip is highly similar. The fact that this full overlap does not occur for other operating conditions indicates that early penetration stages are highly affected by the transient chemistry development, which largely depends on fuel cetane number.

\section{KEYWORDS}

Reacting Diesel spray, tip velocity, radial width, cetane number

\section{INTRODUCTION}

Fuel-air mixing plays a significant role in Diesel engine combustion process. The complexity of the phenomena governing this process has posed a significant challenge to the research community boosting investigations in this field. Both experimental and computational tools have been significantly developed along the last decade and important goals have been achieved [1]-[5].

The definition and characterization of many parameters related to specific spray features brought an important step forward in the understanding of the process [6]-[8]. Thanks to that, conceptual and numerical models have been developed to reproduce the whole Diesel injection process outlining the complex physical and chemical processes that occur behind the experimental observations [1][2].

Most of the studies investigating the air entrainment and mixing process of the spray are performed at non-reacting conditions [6][9][10][11] the inert spray enables an easier approach to determine the mixing field, since the number of species to be accounted for is lower and there are no light emissions coming from the combustion that normally interfere with the optical technique applied. Moreover, the study of the non-reacting spray reduces the unknowns of the problem, which makes it possible to develop more accurate mixing models based on simple momentum conservation and a reduced number of parameters [9][12][13][20]. 
However, it is well know that the spray shape and air entrainment significantly changes as a consequence of the combustion process, presenting a radial expansion and a faster tip penetration [14]-[15][16]. These effects are certainly related to an alteration of the air-entrainment and the mixing process within the spray. The relationship between the combustion process and the shape of the spray can be a key factor to understand in details the mixing field under reacting conditions. Although effects of heat release on flow field and entrainment are a major topic in gas diffusion flames, few studies can be found in the literature that analyse in detail these phenomena under Diesel engine conditions: Pickett et al. presented a quantitative description of the reacting tip penetration [17] which, however, does not show a faster penetration than the non-reacting jet; Desantes et al. [15] performed a more detailed study quantifying the acceleration of the reacting spray tip in terms of the ratio of the tip penetration under reacting and inert conditions (sr/si). Besides, by means of a simple algorithm they demonstrated the possibility of measuring the lift off length by analyzing the spray contour[15]. In a work preceding the present contribution, the shape of a reacting spray with n-dodecane was studied by Payri et al. [18], and a method was developed to quantify the radial expansion caused by combustion. Parametric variations were performed, to evaluate the influence of operating variables on both radial expansion and tip penetration ratio. On the other hand, in a parallel publication [19] the authors evaluated the reacting tip penetration and general combustion characteristics (lift-off length, ignition delay) for a set of binary blends of $\mathrm{n}$-heptane and iso-octane.

All preceding work [15][18][19] has shown that the temporal evolution of the reacting spray can be divided into four stages. Figure 1 illustrates such an evolution based on the inert and reacting tip penetration plots and the ratio of both penetrations at constant time for the reference Spray A condition $\left(22.8 \mathrm{~kg} / \mathrm{m}^{3}, 900 \mathrm{~K}\right.$ and $15 \%$ ambient density, temperature and oxygen content) with $\mathrm{n}$-dodecane [18]. The following stages can be identified:

- Non-reacting evolution, before start of combustion, where the spray follows the same evolution as in the inert reference case, (i.e. a case where no oxygen is present in the air).

- Auto-ignition and stabilization phases, where the penetration ratio plot, followed by a short period where this parameter remains approximately constant. According to Figure 1, this axial expansion effect is around $2 \%$ in the axial direction, which would mean a length increase of $0.6 \mathrm{~mm}$ transition to high temperature combustion is achieved, which can be identified by a local peak in the tip

- Acceleration phase, where the reacting case starts to depart from the inert counterpart due to the rearrangement of local flow to adapt to the new reacting conditions, namely the drop in local density.

- Quasi-steady phase, where the momentum flux is re-balanced along the spray. This results in a constant reacting-to-inert penetration ratio, which remains until the end of injection.

On the other hand, previous work has also shown [18] that the general spatial structure of the reacting spray can be divided into 3 parts (Figure 2): quasi-steady inert spray (from nozzle tip to the flame lift-off length), quasi-steady reacting spray (from lift-off length to the position where the contour stop increasing radially) and transient head (from the end of quasi-steady part to the spray tip). For this quasi-steady situation, the radial increase due to combustion has been shown to be approximately constant along the spray axis. In other words, the radial contour of the reacting spray is simply the result of shifting the inert one by an approximately constant value. This situation is also consistent along the quasi-steady period, (Figure 1). Therefore, a single spatially-time-averaged parameter $\overline{\Delta \mathrm{R}}$ was applied here to evaluate the radial expansion of the quasi-steady reacting part, which is of the order of $1.3 \mathrm{~mm}$ for nominal Spray A conditions. 

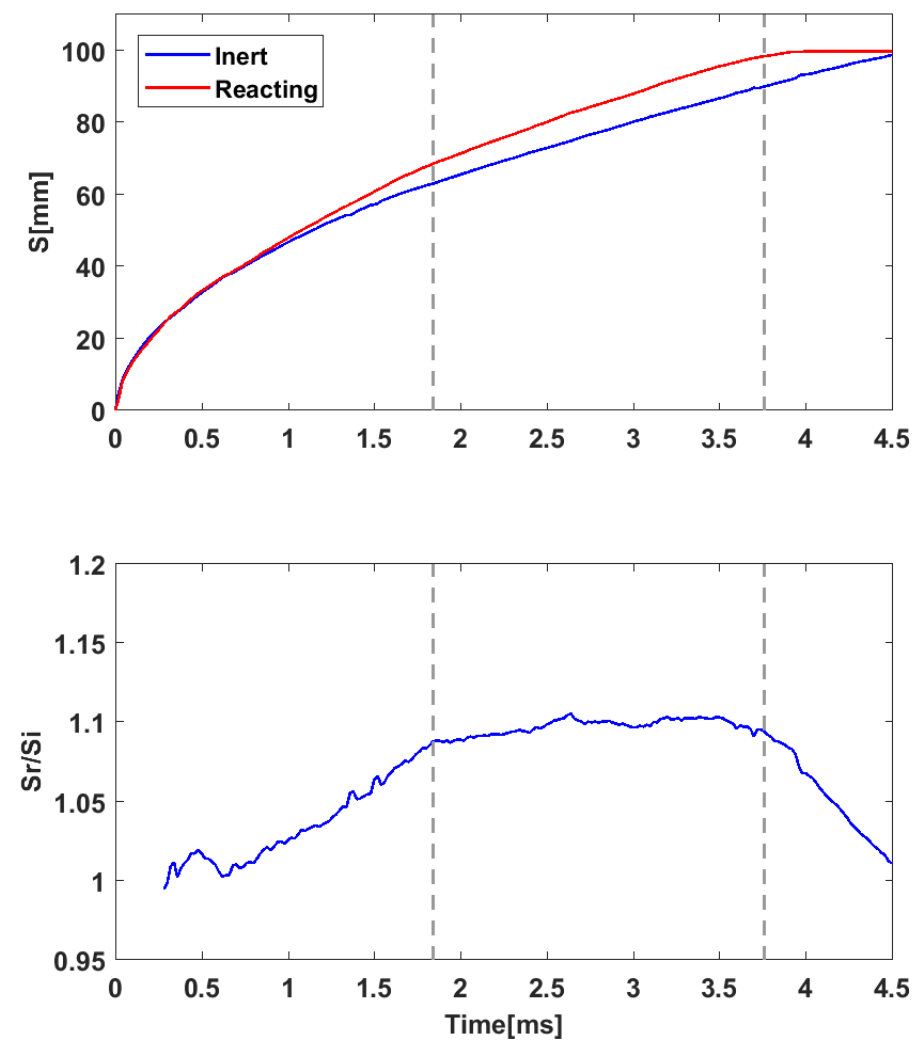

Figure 1 - Definition of tip penetration evolution for nominal Spray A conditions (900K, 15/0\% $\mathrm{O}_{2}, 1500$ bar) with n-dodecane. Top plot shows tip penetration both for inert and reacting conditions, while the bottom one shows the reacting-to-inert penetration ratio [18]

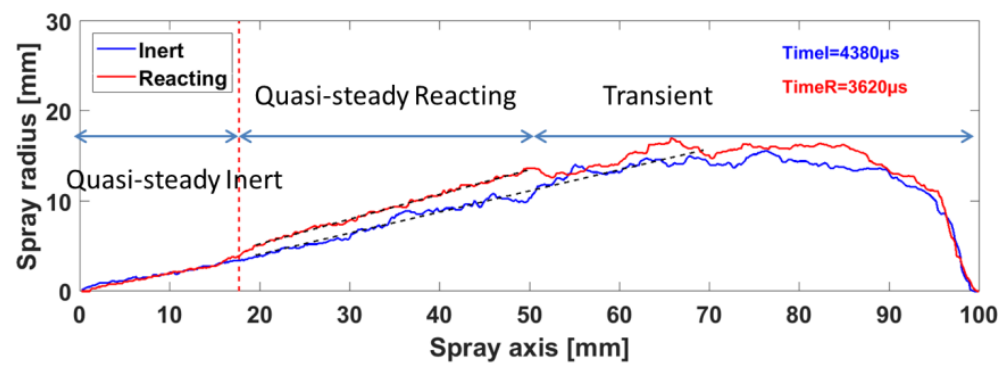

Figure 2 - Radial width for both inert and reacting spray and temporal $\Delta R$ of $n$-dodecane under Spray A condition [18].

Although several parametric variations were carried out in the preceding papers, quantitative predictions of such processes that support the evidences on the reacting spray evolution are missing. Furthermore, the effects of fuel properties and relationship between axial and radial expansion are still not clear. The present work is based on the previously cited experimental database [18][19]. This paper aims at bringing a step forward in this understanding applying the approach used in [18] (comparing spray contour and penetration obtained under inert and reacting conditions) and extending the study using different fuels. Three fuels, n-dodecane [18], n-heptane (PRF0) [19] and a blend (PRF20) which is made up of $80 \% \mathrm{n}$-heptane and $20 \%$ iso-octane in mass [19], were investigated here to highlight the impact of fuel reactivity on the axial and radial expansion after combustion. An improved analysis is presented here that tries to clarify the mechanisms behind the reacting spray tip velocity development, as well the radial dispersion. In order to substantiate the analysis, a 1D spray model [20][21] has been applied

This work has been developed within the framework of the Engine Combustion Network (ECN) activities: ECN is a worldwide group of research institutes that started a collaboration in order to provide high quality data and 
consistent results for modelling purposes [23]. The experiments were performed in a constant-pressure flow facility (CPF) able to reach 15MPa of ambient pressure and 1000K of ambient temperature in a nearly quiescent environment. The wide optical access enables the implementation of a number of non-intrusive diagnostics.

Including the present introduction, this document is composed of five sections. The next two sections give a brief description about the experimental apparatus and modelling tool, respectively. The fourth section presents the different operating conditions which are discussed in this paper. In the fifth section, the experimental and modelling results of tip penetration velocity and radial expansion with different parametric variation are analysed. The last section of the paper summarizes some of the most relevant conclusions of this investigation.

\section{EXPERIMENTAL TOOLS}

This section includes only a brief description of the experimental setup and optical diagnostic technologies that have been used. More detailed information can be found in the reference [18][19].

\subsection{EXPERIMENTAL FACILITY}

A constant-pressure flow test chamber capable of reproducing the in-cylinder thermo-dynamic conditions of a Diesel engine at the time of injection was used. The test rig is a constant-pressure flow (CPF) facility because the Diesel-like conditions are reached by means of a continuous flow of a high temperature and high pressure gas through the test chamber. Three wide quartz windows ( $120 \mathrm{~mm}$ diameter) enable a favourable optical access to the test section. A separated cooling system was used for the injector: the temperature of the coolant was adjusted in order to maintain a constant nozzle tip temperature. A complete description of the facility is given in [24].

\subsection{OPTICAL TECHNIQUES}

Data recorded by two simultaneous imaging techniques were employed in this study: High-speed Schlieren and Time averaged $\mathrm{OH}^{*}$ chemiluminescence. A sketch of the experimental layout is presented in Figure 3 . The details of the measurements and of the optical setup employed are given in [18][19].

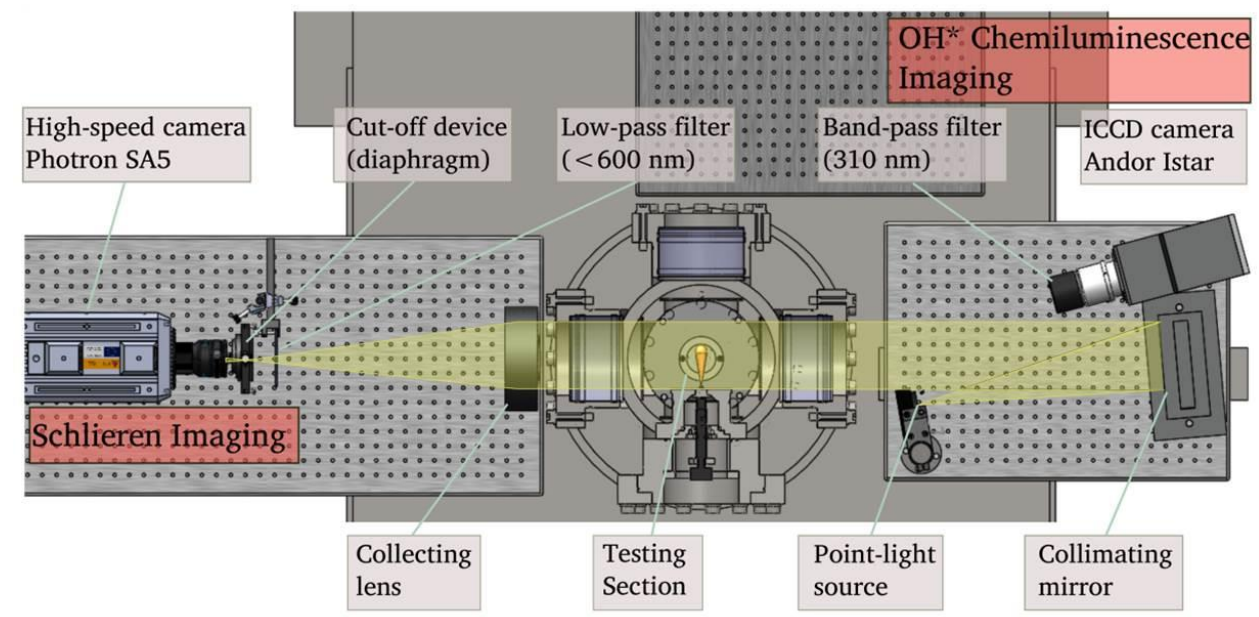

Figure 3 - Experimental layout for reference measurements [18][19].

\subsubsection{High speed schlieren imaging}

A conventional Schlieren single-pass arrangement was employed to detect the complete spray boundaries at high temperature and high pressure conditions. Schlieren imaging technique enables to detect gradients in the refractive index of a transparent medium [25]. The technique relies on the deviation of a light beam produced when light passes through non-homogeneous fluids.

Images captured in the tests were processed following an intensity-based criterion and applying a dynamic background subtraction: the methodology, described in details in the work by Benajes et al [26], proved to be robust, 
and provides binarized images of the spray region. After that, a processing algorithm is applied to derive both spray tip penetration (s) and a representative radial contour, according to the procedure described in detail in [18] . In addition, besides spray tip penetration, ignition delay was also obtained from Schlieren images based on the analysis on the total intensity increment within the spray between each two consecutive images. Details of this processing methodology can be found in [26], where the corresponding time of the peak of the total intensity increment was defined as ignition delay, and it was also validated by broadband chemiluminescence technique.

\subsubsection{Time averaged $\mathrm{OH}^{*}$ chemiluminescence}

The high-temperature heat release region of a Diesel spray is generally related with light emission by the $\mathrm{OH}^{*}$ radicals decaying to their ground state. These light emissions have an important peak at $309 \mathrm{~nm}$. This technique was applied here to quantify the lift-off length (LOL) which is defined as the distance from the injector tip to the base of the flame [27][28]. Detailed information about the camera setup, procedure followed and the results have been already presented in [26].

\section{THEORETICAL TOOLS. 1D SPRAY MODEL}

A previously existing 1D spray model [19]-[22] has been used to substantiate the analysis of experimental results. The model solves 1D conservation equations of axial momentum and mixture fraction in terms of the axial distance to the nozzle. Radial dispersion is considered by means of radial integral terms in the model that assume Gaussian self-similar profiles for axial velocity and mixture fraction. The model has been successfully used to predict inert spray penetration and liquid length [19][20]. Compared to similar models in the literature, where local density is assumed to be radially homogeneous [29][30] and is not always coupled into the momentum equations [30], the present approach feeds local density from state relationships into conservation equations from the radial distribution of mixture fraction. This makes it possible to include the effects of heat release onto the flow by modifying the distribution of local density as a consequence of heat release, which will result in a modified velocity distribution.

Under inert conditions, inputs for the model are

- Nozzle mass and momentum fluxes.

- Fuel composition, temperature and density.

- Ambient gas composition, pressure, temperature and density.

- Spray cone angle.

Except for spray cone angle, inputs are measured quantities. The latter parameter has been used as a calibration parameter based on the difference between experimental and modelled tip penetration for the nominal inert conditions, which is common practice in this type of models [31].

When dealing with reacting conditions, a simplified Burke-Schuman approach is followed, with a single-step reaction assumed for chemistry. Due to the absence of chemical kinetic effects, which would enable the prediction of ignition delay and lift-off length, two additional inputs for the model are

- Ignition delay $t_{s o c}$ to identify when combustion will start. The 1D model assumes that a step transition from inert to reacting conditions occurs at ignition delay $\left(t=t_{s o c}\right)$.

- On-axis mixture fraction at the lift-off length $\left(f_{c l, L O L}\right)$, which will enable the model to spatially separate the location where the spray transitions from inert to reacting conditions. This is usually derived from the experimental lift-off length distance, and a model calculation under inert condition, and can be converted later to equivalence ratio at the lift-off length.

In addition to the previous parameters, information on the radial expansion process as a consequence of the transition from inert to reacting states has to be included. Initially, this effect was accounted for by means of a socalled 'reacting spray cone angle' [21]. However, the analysis of more recent experimental information [18] has shown that the macroscopic geometry of a reacting spray rather keeps a cone angle similar to the inert one, but with an increased width. Therefore, the present approach will consider that the radial expansion of the reacting spray is 
defined in terms of a single parameter, namely a predicted radius increase $\Delta R$, which is calculated on the basis of the following additional hypotheses (Figure 4):

- Radial expansion process only happens at the time of start of combustion $\left(t=t_{\text {soc }}\right)$, which is an input parameter for the model. This is consistent with the simplified combustion description in the model, which considers that the spray transitions from inert to fully reacting conditions at a given ignition delay timing, within a zero duration interval.

- At start of combustion the spray is only allowed to expand from the lift-off length location LOL till the spray tip $\mathrm{s}_{\text {soc }}$. Besides, expansion only happens radially, and is defined by a single $\Delta \mathrm{R}$ value, which is constant along the reacting part of the spray. Axial expansion has been neglected compared to the radial one for two main reasons. First, as discussed in the Introduction section, experiments suggest that it has a smaller value $(0.3$ $\mathrm{mm}$ axial vs $1.3 \mathrm{~mm}$ radial). Furthermore, volume increase is linear with axial increase, while it is quadratic with radial increase, which means the second influence is much more important for later flow evolution.

- Neither the distribution of the mixture fraction on the axis nor the self-similar radial profile is modified in the inert-to-reacting transition process occurring at start of combustion. However, subsequent evolution of the reacting spray will obviously be affected by the drop in density due to heat release.

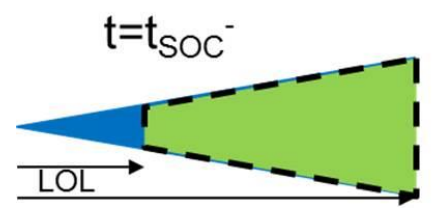

$\mathrm{S}$

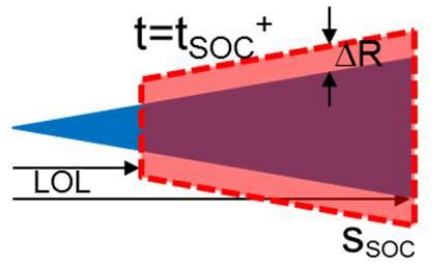

Figure 4 -Schematic showing the simplified inert (left, $t=t s o c-)$ to reacting (right, $t=t s o c+$ ) transition as described by the model

The equation derived to calculate the radial expansion states that the mixture undergoes a transition from inert to reacting conditions keeping a constant mass. This can be expressed in a formal way by the integral of the total mass between both $\mathrm{x}=\mathrm{LOL}$ and the spray tip $\mathrm{x}=\mathrm{s}_{\text {soc }}$ as (Eq. 1 ), which is evaluated at start of combustion, $\mathrm{t}=\mathrm{t}_{\mathrm{soc}}$.

$$
\iint_{L O L}^{s_{\text {SOC }} R} \rho_{0} \rho_{\text {inert }} \cdot 2 \pi r \cdot d r \cdot d x=\iint_{L O L}^{s_{S o c} R+\Delta R} \int_{0} \rho_{\text {react }} \cdot 2 \pi r \cdot d r \cdot d x
$$

The same integral function appears on both sides of the equation, with the left hand side term being integrated under inert conditions and the right hand side one under reacting ones, just after start of combustion. Because the mixture state (mixture fraction distribution) is known just at start of combustion, one can apply the previous equation to solve $\Delta R$ and fully accounting for a non-homogeneous density distribution.

A simplified analysis based upon the same equation is presented in Appendix A, which shows that for a uniform density situation, $\Delta \mathrm{R}$ depends explicitly on two parameters:

- Inert-to-reacting density drop $\rho_{\text {inert }} / \rho_{\text {react }}$

- Location with respect to the nozzle of the ready-to-burn mixture, i.e. the geometry and location of the reacting mass in terms of $L O L$ and $s_{s o c}$. The further downstream the ready-to-burn mixture is located, the larger the induced radial expansion is, mainly due to a larger mass (radius) within each spray cross-section.

The 1D model solves exactly the same problem, but within a non-uniform density distribution, meaning a spacedependent inert to reacting density drop, which is closer to reality. For a given spray case, such density drop depends on pure fuel and air thermal state and composition. This enables the consideration of cases where, for example, ready-to-burn mixture is located further downstream, for which radial expansion will change not only because of the larger initial radius, but also because of the modification of the local density drop due to a nonuniform mixture. 


\section{TEST CONDITIONS}

One of the main objectives of this paper is to study the effects of fuel properties on the transient reacting spray evolution. Three fuels, namely $n$-dodecane, $n$-heptane (PRFO) and one binary blend of Primary Reference Fuels (PRF20, made up of $80 \% \mathrm{n}$-heptane and $20 \%$ iso-octane in mass) have been investigated here. Some general chemical and physical properties of the three pure components are shown in Table 1 . In practical terms, thermochemistry properties of all three fuels are highly similar. In fact, 1D model calculations of local conditions in terms of state relationships (Figure 5) show that the mixture state under both inert and reacting conditions (temperature, density) is quite similar for all three fuels, which means that the expected differences in flow development among fuels are mainly related to chemical kinetics, which will set the pace for the transition from inert to reacting conditions.
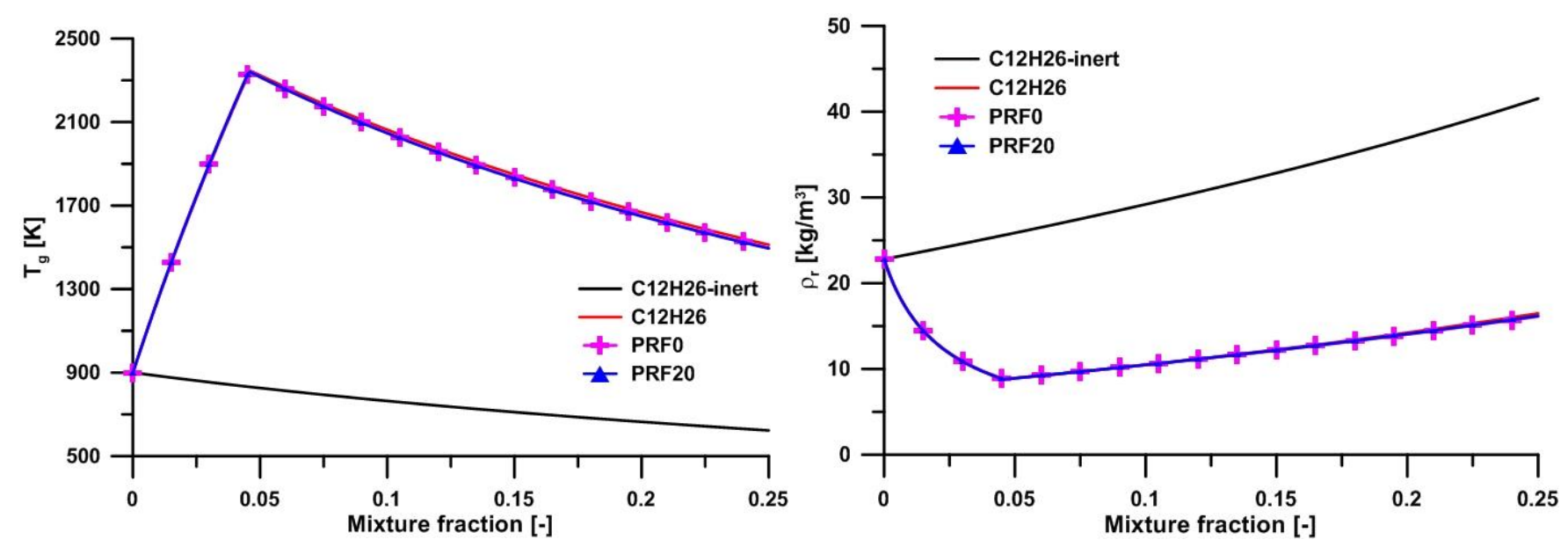

Figure 5 -State relationships for the three considered fuels. Temperature (left) and density (right) versus mixture fraction for $\mathrm{C} 12 \mathrm{H} 26$, inert, and C12H26, PRFO and PRF2O reacting. Nominal Spray A conditions.

As mentioned above, this study is based on an existing database from [18][19] where the standard Spray A injector within ECN group has been used. The injector has a single-hole nozzle with a nominal diameter of $90 \mu \mathrm{m}$ (Serial No. 210675). The parametric variation in the injection parameters (injection pressure), thermodynamic conditions within the chamber (ambient temperature and ambient density) and oxygen concentration sweep are shown in Table 2. A long injection energizing time was set as $3.5 \mathrm{~ms}$ for every operating condition in order to achieve a quasi-steady state flame. For each operating condition, 8 injection cycles were recorded for n-dodecane and 15 for PRF0 and PRF20.

\begin{tabular}{lllll}
\hline Fuel & $\rho_{f}[\mathrm{~kg} / \mathrm{m} 3]$ & LHV [MJ/kg] & Tboil [K] & CN[-] \\
\hline $\begin{array}{l}\text { n-dodecane } \\
\text { (C12H26) }\end{array}$ & 752 & 44.2 & 356.2 & 87 \\
n-heptane (PRF0) & 684 & 44.6 & 371.5 & 53 \\
iso-octane (PRF100) & 690 & 44.3 & 372.4 & 14
\end{tabular}

Table 1 - Fuel properties for the pure components investigated in the present contribution.

\begin{tabular}{lllll}
\hline Fuel & $\mathbf{T}_{\mathbf{g}}[\mathrm{K}]$ & $\mathbf{P}_{\text {inj }}[\mathrm{bar}]$ & $\mathbf{\rho}_{\mathbf{g}}[\mathbf{k g} / \mathbf{m 3}]$ & $\mathbf{O}_{\mathbf{2}} \%[\%(\mathbf{v o l})]$ \\
\hline C12H26 & $800,850,900$ & $500,1000,1500$ & 22.8 & $0,15,21$ \\
PRF0 & 900,1000 & $500,1000,1500$ & 22.8 & $0,15,18,21$ \\
PRF20 & 900,950 & $500,1000,1500$ & 22.8 & $15,18,21$ \\
PRF100 & 900 & $500,1000,1500$ & 22.8 & 0 \\
\hline
\end{tabular}

Table 2 - Operating conditions investigated in the present contribution. 


\section{RESULTS AND DISCUSSION}

This section summarizes the main outcomes of the present investigation. The first two subsections deal with the analysis of tip penetration velocity, both for the baseline conditions (5.1) and for other parametric variations (5.2). Special attention will be paid to the quasi-steady penetration phase. The third subsection (5.3) summarizes results from the radial expansion study with different fuels.

\subsection{ANALYSIS OF TIP PENETRATION VELOCITY - BASELINE CONDITIONS}

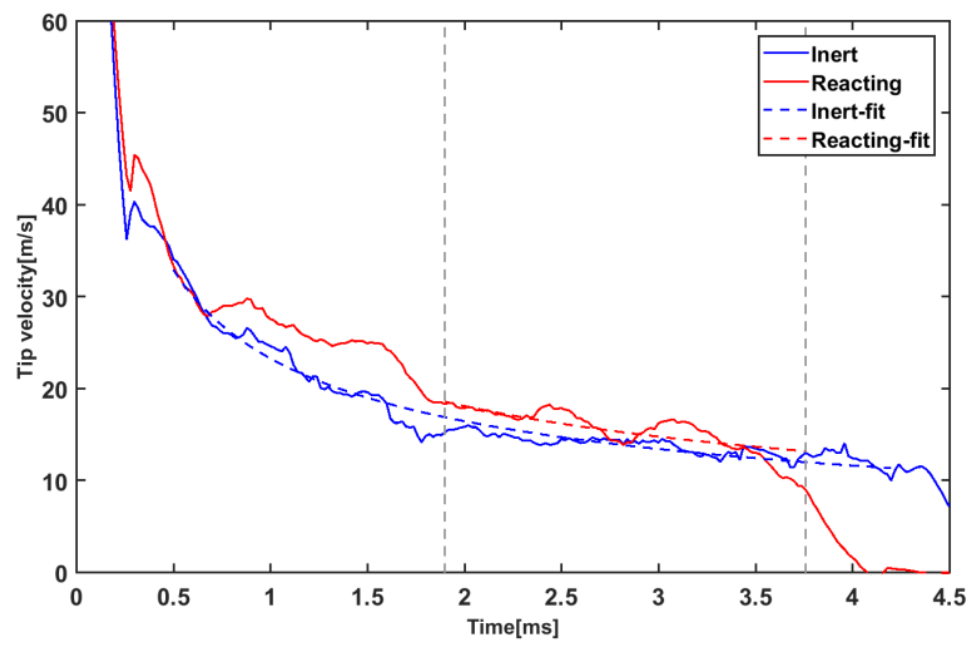

Figure 6 - Time evolution of tip penetration velocity for nominal Spray A conditions with $n$-dodecane (Figure 1). Vertical dashed lines represent the quasi-steady interval.

As discussed in the introduction section, reacting tip penetration undergoes several stages highly influenced by the strong coupling between chemistry and fluid dynamics, eventually leading to the quasi-steady penetration phase. To avoid the cumulative effect of the different stages on the analysis of this last phase, the analysis in the present work will be performed in terms of the spray tip penetration velocity, i.e. the time-derivative of the tip penetration. This should help better characterize the instantaneous evolution of spray tip during this quasi-steady phase. Figure 6 shows the time evolution of this characteristic velocity as calculated from tip penetration (Figure 1) for both the inert and reacting cases of the nominal Spray $A$ condition with $n$-dodecane. A clearly decreasing trend with time is observed in both cases, with a more oscillating evolution in the reacting case due to the different stages mentioned in the Introduction section.

As shown in the literature [6][13][32][33], spray tip velocity for an inert spray is inversely proportional to square root of time. Following this idea, the experimental tip penetration velocity has been fitted to Eq (2) for both inert and reacting conditions:

$$
\frac{d s}{d t}=\frac{k}{\sqrt{t}}
$$

While the fit is performed from $0.5 \mathrm{~ms}$ ASOI to $4.2 \mathrm{~ms}$ ASOI for the inert cases, it is only applied during the quasisteady penetration period for the reacting ones, as defined in Figure 1, i.e. during the period where the reacting to inert penetration ratio $\left(s_{r} / s_{i}\right)$ is constant. The dashed trend lines in Figure 6 show that for both cases Eq (2) describes adequately the tip penetration evolution. The $k$ value for inert conditions can be derived from the consideration of a quasi-steady constant density mixing controlled spray, [33] leading to the theoretical constant $k_{t h}$ according to Eq 3.

$$
k_{t h}=\sqrt[4]{\frac{\log (100)}{8 \pi}} \cdot \sqrt[4]{\frac{\dot{M}_{0}}{\rho_{a}}} \cdot \frac{1}{\sqrt{\tan (\theta / 2)}}
$$


This means that, for an inert spray, tip velocity only depends on momentum flux $\dot{M}_{0}$, air density $\rho_{a}$ and spreading angle $\theta$. Figure 7 shows that for the investigated conditions under the present study, the inert tip penetration follows quite accurately the description in Eq 3, where experimental momentum flux and density values have been used, together with a constant angle $\theta=24^{\circ}$ Note that three pure fuels are considered under inert conditions, namely n-dodecane ( $\mathrm{C} 12 \mathrm{H} 26)$, n-heptane (PRFO) and iso-octane (PRF100), so that any tested blend in-between should also produce the same results.

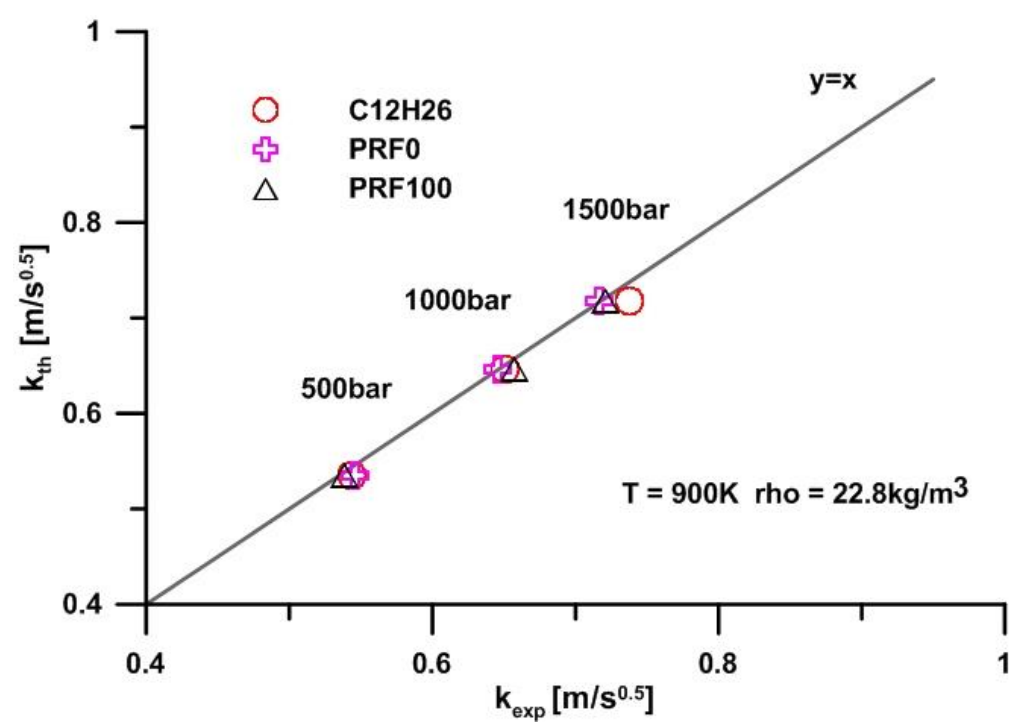

Figure 7 - Comparison of theoretical tip penetration velocity $k$ constant according to Eq. 3 with experimental values for the investigated inert conditions. A constant angle $\theta=24^{\circ}$ has been used in Eq. 3 .

The fitted line under reacting condition in Figure 6 indicates that a similar behavior of the reacting spray to the inert one can also be expected along the quasi-steady period. If this behavior is quantified in simple terms by means of Eq. 3 , momentum flux influence should be the same under both inert and reacting conditions, while for the latter case a density drop and increase spreading will be the main factors creating a tip velocity departure from the inert one. The extension to reacting conditions could be made by assuming a modified density and radial width parameter. However, no simple a priori solution exists due to the wide range of densities existing within the reacting spray. This is why the use of the 1D model is pertinent, especially if the focus on the quasi-steady phase is made, which removes the necessity of a detailed chemistry analysis.

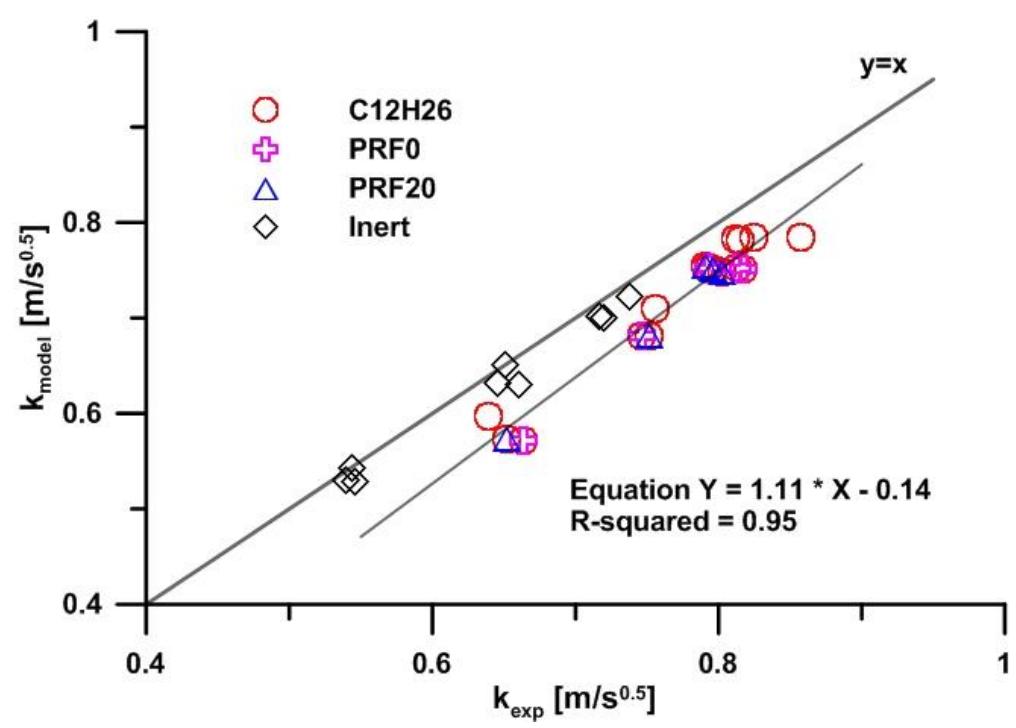

Figure 8 - Comparison of tip penetration velocity $k$ constant from 1D model vs experimental values for the investigated conditions.

Figure 8 shows an overall comparison of the $k$ values as derived from both $1 \mathrm{D}$ model and experiments for all conditions in the present study. Again, predictions for the inert case are also good for the 1D model, which could be 
expected due to the fact that the derivation of Eq. 3 is based upon similar hypotheses as the 1D model. As for reacting spray, they follow an adequate trend, but model results are slightly below the experimental ones. Using Eq. (3) as a basis, one could argue that the reasons for underestimation could be in a non-adequate consideration of momentum flux, local density or radial spread. None of these gives a satisfactory explanation based upon the following: First, momentum flux just depends on the injection pressure and chamber pressure, with 1.3 bar difference between inert and reacting conditions, therefore this parameter is essentially constant. Second, local density has an inverse relationship to tip velocity. Therefore, the observed trend should mean that the model overestimates local density, delivering a reduced penetration. However, because of the very fast transition to reaction in the model, local densities should be rather underestimated compared to reality. Finally, Section 5.3 will show that radial expansion in the model is lower than in experiments, which again should lead to a faster penetration rate. All in all, none of the three main parameters governing tip penetration seem to give a satisfactory explanation for the observed deviation. The divergence of the model compared to experiment may probably result from the description of the transient vortex area at the tip of the spray. Coming back to Figure 2, the transient head occupies around $30 \%$ of the total spray length under inert conditions, while it reaches around $50 \%$ under reacting ones. Probably this highly simplified description cannot consider the full phenomena happening during a highly transient reacting spray evolution. However, the model can still be valid for analysis purposes, as it shows a good sensitivity towards experiments.

\subsection{ANALYSIS OF TIP PENETRATION VELOCITY - PARAMETRIC VARIATIONS}
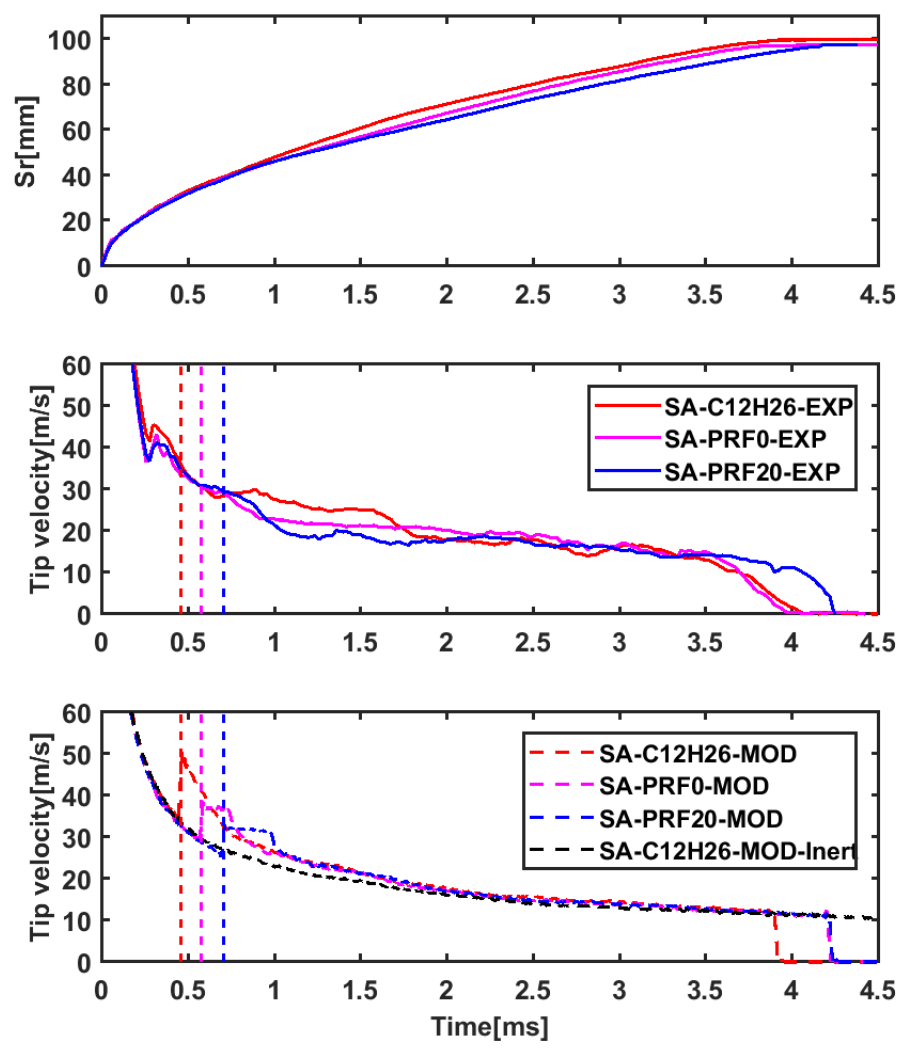

Figure 9 - Effect of fuel type on penetration-derived information for nominal Spray A conditions (900K, 15/0\% $\mathrm{O}_{2}$, 1500 bar). Top plot: experimental penetration. Middle: experimental tip velocity Bottom: model tip velocity. Vertical dashed lines indicate auto-ignition time.

Starting from the baseline condition, namely nominal Spray A with $n$-dodecane, the first parametric variable to be analyzed will be fuel type. Figure 9 shows a comparison of spray tip velocity for three fuels under the same operating conditions. The ignition delay has also been shown in terms of vertical lines. The sequence C12H26->PRF0->PRF20 (in decreasing cetane number) shows a later timing for inert-to-reacting transition. If analyzed in terms of spray tip penetration (top plot) one can observe that the lower the fuel reactivity the slower the reacting tip penetration is. However, if analyzed in terms of tip velocity (middle plot), the conclusions are not the same. In this case, main differences among fuels occur during the autoignition and acceleration phase. Keeping again the same sequence in 
decreasing cetane number, one can observe that the acceleration phase is shifted later in time, starting from 0.6 to $1.6 \mathrm{~ms}$ for $\mathrm{C} 12 \mathrm{H} 26,0.9$ to $2 \mathrm{~ms}$ for PRF0 and finally 1.5 to $2.5 \mathrm{~ms}$ for PRF20. The interesting feature, however, is that the later time development of spray tip velocity is the same regardless of fuel, i.e. the quasi-steady phase shows identical tip velocity for all three fuels. This means that the observed slower tip penetration (top plot) of the lower cetane number is mainly due to differences in the early stages of the penetration, which cannot be compensated later due to a similar penetration velocity. A similar trend is obtained from the modelling results (bottom plot). Because transition in chemistry in modelling is much faster than in experiments, one can observe an earlier collapse of the three cases, but behavior is also independent of fuel type.

Accordingly, for the investigated conditions, fuel cetane number has an effect on when the inert to reacting transition occurs (ignition delay), as well as how fast this transition is. A quasi-steady penetration period has been confirmed, in which spray tip velocity is the same for the investigated fuels, mainly due to the fact that they have very similar thermochemistry properties.

The effects of fuel properties observed for the nominal conditions can be extended to the whole set of operating conditions considered, as summarized in Figure 10. Here only the quasi-steady phase tip velocity constant $k$ is analyzed. Again, fuel cetane numbers seen to have negligible effects on $k$ value. In other words, tip velocity of the three fuels is the same during quasi-steady phase.

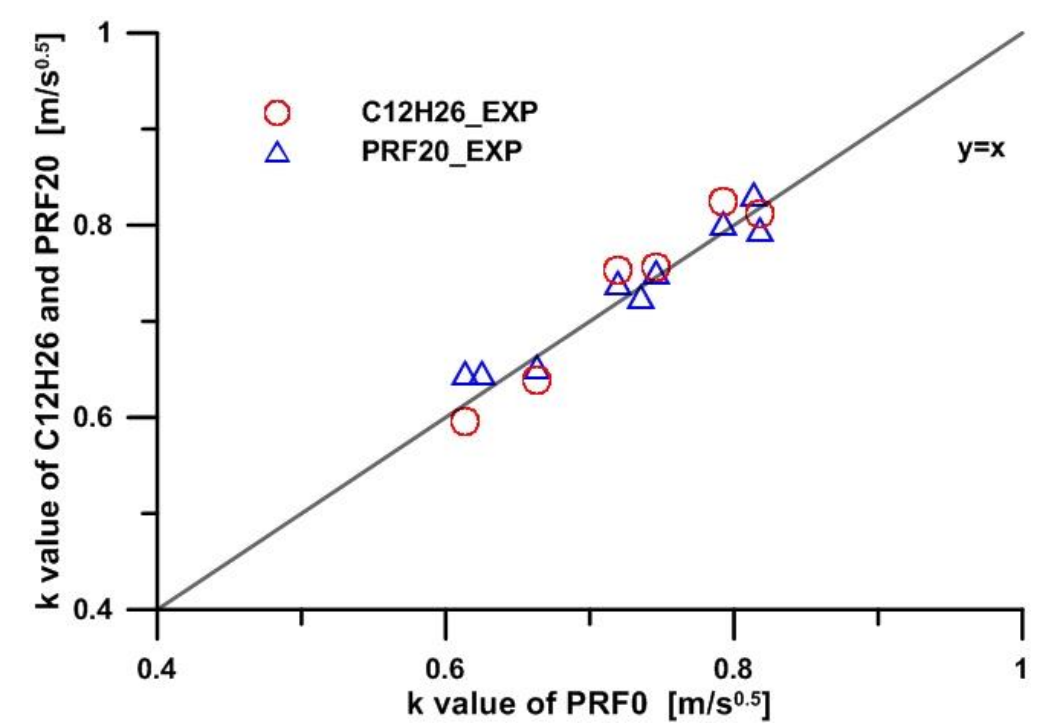

Figure 10 - Analysis of fuel effects on tip penetration experimental $k$ constant.

Figure 11 presents the effects of ambient gas temperature (top row), oxygen (middle row) and injection pressure (bottom row) on spray tip velocity temporal evolution (left column) and $k$ value for all fuels (right column). In the latter case, solid symbols represent experimental results, while hollow ones correspond to 1D modelling results. $k_{\text {th }}$ values from Eq 3 are also included as a reference to represent the inert spray case. This parameter does not change with different fuels and ambient temperature when keeping a constant injection pressure (i.e. momentum flux), air density and spreading angle[6][34]. A trend line has been included to qualitatively show the effect of a parametric variable on the experimental tip velocity. Due to the previously discussed negligible influence of fuel properties within the present study, a single trend line has been irrespective of fuel type.

$\mathrm{k}$ values of reacting cases are found to be always larger than $\mathrm{k}_{\mathrm{th}}$, which means reacting spray tip velocity during the quasi-steady phase is always faster than the inert one because of the combustion-induced density drop. On average, increases in tip velocity are around $15 \%$ compared to the inert case, which is linked to a combustion-induced decrease in entrainment. This is consistent with recent local velocity measurements [22] for $n$-dodecane under the same boundary conditions as in the present experiment, which showed an increase of around $50 \%$ in spray axis velocity in the reacting case compared to the inert one. 

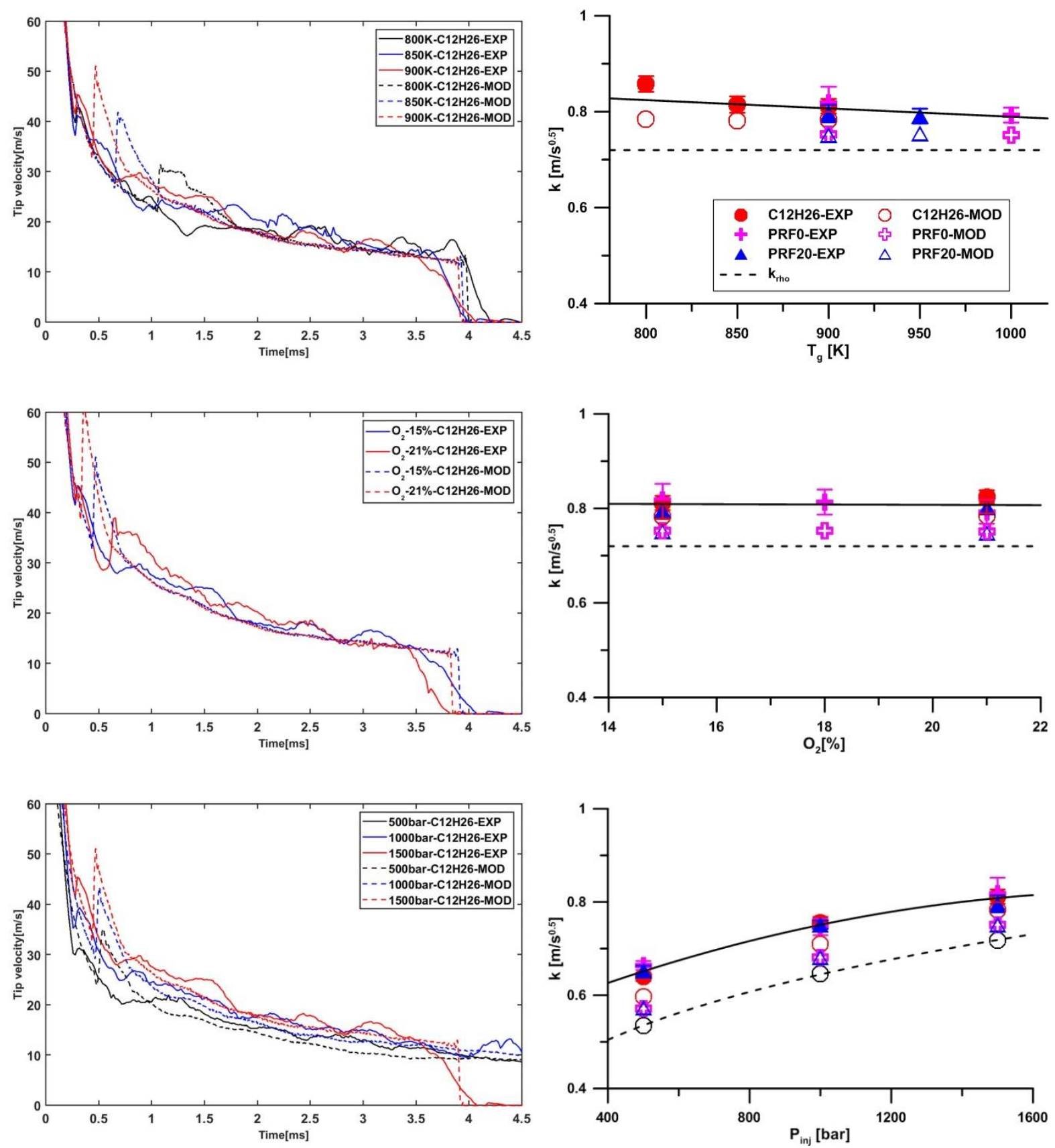

Figure 11 - Effect of air temperature (top row), oxygen (middle row) and injection pressure (bottom row) on tip velocity penetration. Left, timeresolved tip velocity versus penetration for $n$-dodecane. Solid lines correspond to experimental values, while dashed ones correspond to 1D modelling results. Right, normalized penetration vs ambient conditions for all investigated fuels. Solid symbols represent experimental results, while the hollow symbols represent 1D modelling results.

When considering the time development of tip velocity for $\mathrm{n}$-dodecane, different evolutions are observed depending on the ambient temperature and oxygen concentration, due to strong differences in ignition delay and acceleration phases. However, this parameter tends to a very similar value during quasi-steady phase for all three ambient temperature and oxygen values, i.e. none of these operating variables has a strong effect on the quasi-steady tip velocity (Figure 11, left) and therefore on $\mathrm{k}$ value (Figure 11, right). While velocity constant still shows a slight sensitivity to ambient temperature, the evolution with oxygen is clearly flat.

Figure 12 shows the local reacting to inert density ratio $\left(\rho_{r} / \rho_{i}\right)$ from the 1D model state relationships as a function of mixture fraction. For all conditions, this parameter reaches a minimum at stoichiometric conditions, with increasing values towards both rich and lean sides. When considering the ambient temperature variation, such density ratio slightly increases with higher temperature all over the mixture fraction range, i.e. local flame density increases with higher ambient temperature. This can help explain the slightly decreasing trend in $\mathrm{k}$ value with higher temperature in Figure 11, i.e. flow progresses within a slightly higher density field, which will result in lower velocity due to momentum conservation (Eq. 3). In the case of ambient oxygen, local density drop is noticeably different at 
stoichiometric conditions, but falls upon a single trend in the lean range. Taking into account that the quasi-steady tip penetration phase occurs late in time, when a relatively small proportion of the spray is at rich conditions, the local density drop in most of the spray will not change depending on the ambient oxygen content, which is consistent with the insensitivity of tip velocity constant to oxygen.

Finally, when changing injection pressure (Figure 11 bottom), tip velocity happens at different momentum flux values, so the different time evolutions do not overlap with each other, not even during the quasi-steady phase. Higher injection pressure values result in a faster tip velocity due to the higher momentum flux, consistently with inert conditions (Eq. 3). Furthermore, sensitivity of $\mathrm{k}$ values to injection pressure is similar for both reacting and inert configurations. Just as an example, when moving from $\mathrm{P}_{\text {inj }}=500$ bar to 1500 bar the reduction in velocity constant is $\Delta \mathrm{k}=0.16 \mathrm{~m} / \mathrm{s}^{0.5}$ for the reacting and $\Delta \mathrm{k}=0.18 \mathrm{~m} / \mathrm{s}^{0.5}$ for the inert case. No influences of injection pressure on local density can be expected, and therefore this confirms a similar influence of injection pressure for both inert and reacting conditions. It could be argued that scalar dissipation rate effects might be important on local temperature and therefore density values, but the small size of the nozzle results in a fast mixing and therefore low gradients can be expected in the burning zone with consequently similar reacting density values.
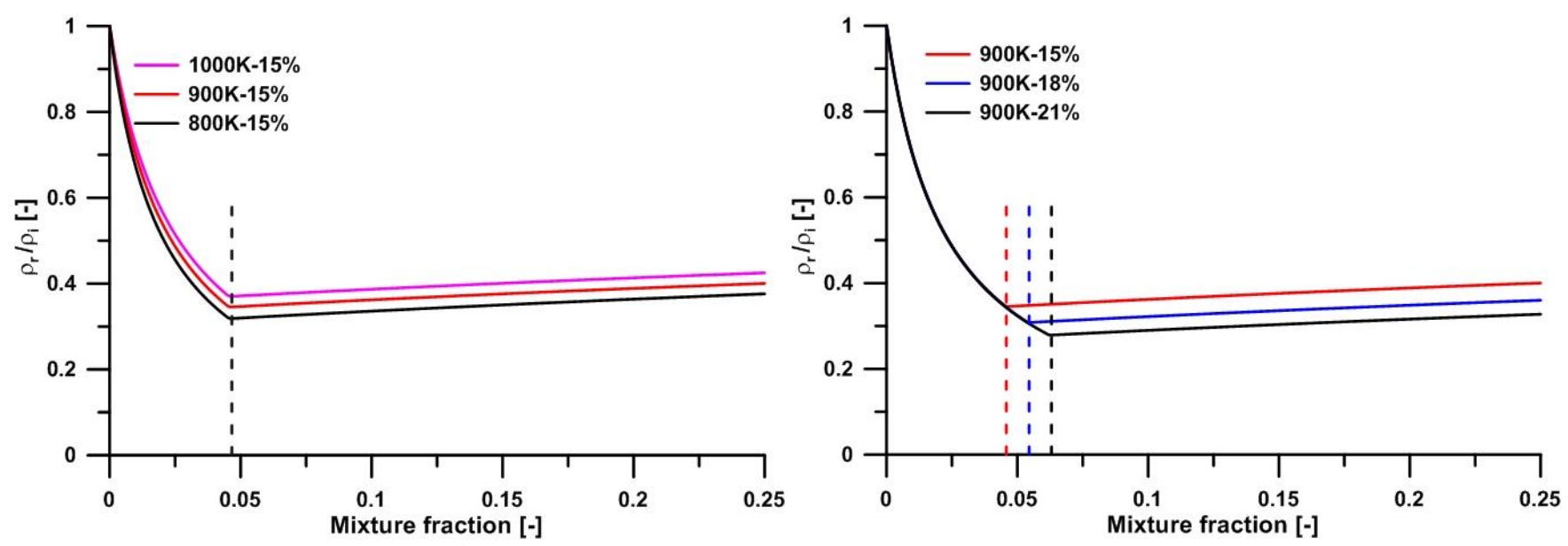

Figure 12 - Local reacting to inert density ratio as a function of mixture fraction for ambient gas temperature (left) and oxygen (rigth) sweep. Fuel is $P R F O, \rho g=22.8 \mathrm{~kg} / \mathrm{m3}, 02=15 \%$. Vertical dashed lines indicate stoichiometric mixture fraction

To further confirm the previous findings, a comparison of cases with simultaneous modification of more than one parametric variable has been carried out. Operating conditions are summarized in Table 3. Three cases have been selected where reactivity difference among the fuels is compensated by ambient oxygen content to reach almost constant ignition delay and lift-off length (only $t_{\text {soc }}$ of $n$-dodecane is slightly shorter). In addition, a fourth case with a shorter ignition delay and lift-off length by using n-dodecane (the most reactive fuel) and a high ambient oxygen is also shown here as a reference of a much more reactive case.

\begin{tabular}{cccccccc}
\hline Fuel & $\mathrm{P}_{\text {inj }}[\mathrm{bar}]$ & $\rho_{\mathrm{a}}[\mathrm{kg} / \mathrm{m} 3]$ & $\mathrm{O}_{2}[\%]$ & $\mathrm{T}_{\mathrm{g}}[\mathrm{K}]$ & $\mathrm{t}_{\mathrm{soc}}[\mathrm{ms}]$ & $\mathrm{LOL}[\mathrm{mm}]$ & $\mathrm{k}\left[\mathrm{m} / \mathrm{s}^{0.5}\right]$ \\
\hline C12H26 & 1500 & 22.8 & 15 & 900 & 0.46 & 17.7 & 0.78 \\
PRF0 & 1500 & 22.8 & 18 & 900 & 0.52 & 17.6 & 0.81 \\
PRF20 & 1500 & 22.8 & 21 & 900 & 0.53 & 18.3 & 0.80 \\
\hline C12H26 & 1500 & 22.8 & 21 & 900 & 0.35 & 12.6 & 0.82 \\
\hline
\end{tabular}

Table 3 - Selected operating conditions for the comparison of tip velocity at constant ignition delay and lift-off length values (first three cases), and a high reactivity case (fourth case). 

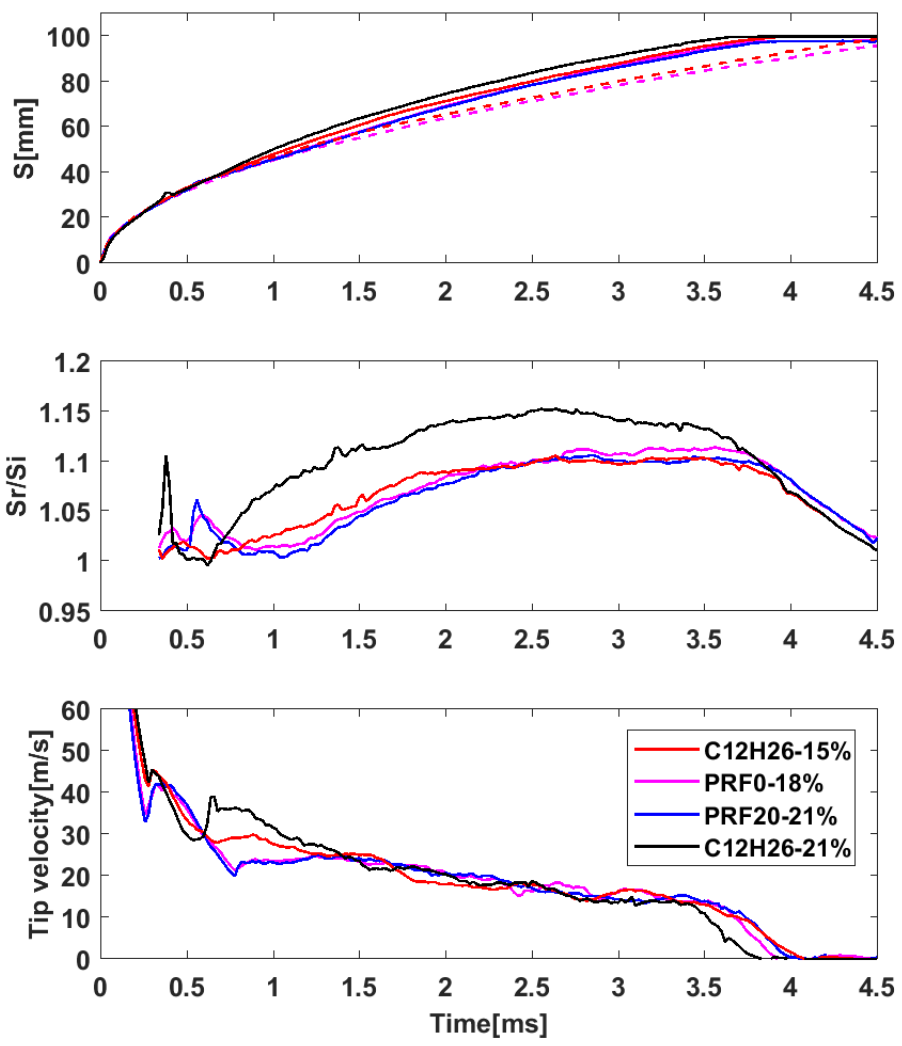

Figure 13 - Spray tip penetration (top), penetration ratio (middle) and spray tip velocity (bottom) for cases in Table 3.

Figure 13 shows the temporal evolution of spray tip penetration, reacting to inert penetration ratio and velocity of the selected cases. Because of a little shorter ignition delay, spray tip of n-dodecane starts accelerating earlier, while the difference between PRFO and PRF20 is negligible. As expected according to the previous analysis on the isolated effects of oxygen and fuel cetane number, tip velocity of all three fuels is coincident when it comes to the quasisteady phase. Similar k values are observed in Table 3. The interesting feature in this particular study is that, due to the highly similar ignition delay and lift-off length values, not only the quasi-steady phase, but also the initial autoignition and acceleration phases are certainly very similar among all three cases, which in the end results in an almost identical tip penetration evolution. Compared to that, the most reactive case ( $n$-dodecane with $21 \%$ oxygen in ambient) ignites earlier and accelerates much faster, although the quasi-steady phase progresses at the same velocity as for the other cases.

Summing up, for the investigated fuels the existence of a quasi-steady tip penetration phase has been demonstrated in terms of the development of a characteristic tip velocity. Neither ambient oxygen nor temperature has a meaningful effect on this variable due to the low or non-existent modification of local density drop. Injection pressure has a similar effect on reacting tip velocity as in inert sprays. This indicates that, similarly to inert sprays, the dynamics of the quasi-steady phase is governed by momentum flux and density, scaled with a factor to account for heat release.

The previous analysis confirms that chemical kinetics, either in terms of fuel type, ambient oxygen or even temperature, has a role mainly on the initial spray dynamics. Chemistry defines when the transition to the reacting state is triggered, launching the acceleration phase, which is also different depending on the chemical evolution.

1D spray model has been able to reproduce the spray tip penetration under transient reacting conditions with some limitations. First, the acceleration phase cannot be captured because of the simplified chemistry approach, namely the step transition from inert to fully reacting conditions. On the other hand, during the quasi-steady phase the model predicts an acceleration of the reacting versus the inert case which is in line with experiments, but with lower sensitivity to operating conditions. 


\subsection{ANALYSIS OF COMBUSTION-INDUCED RADIAL EXPANSION}

Although a detailed analysis of the radial expansion $\overline{\Delta R}$ was already published in [18] for $n$-dodecane, this section adds further discussion on this parameter with a twofold objective

- To present the experimental trends for the additionally investigated fuels.

- To provide a justification of the observed experimental trends in radial expansion based upon the 1D model description in Section 3.
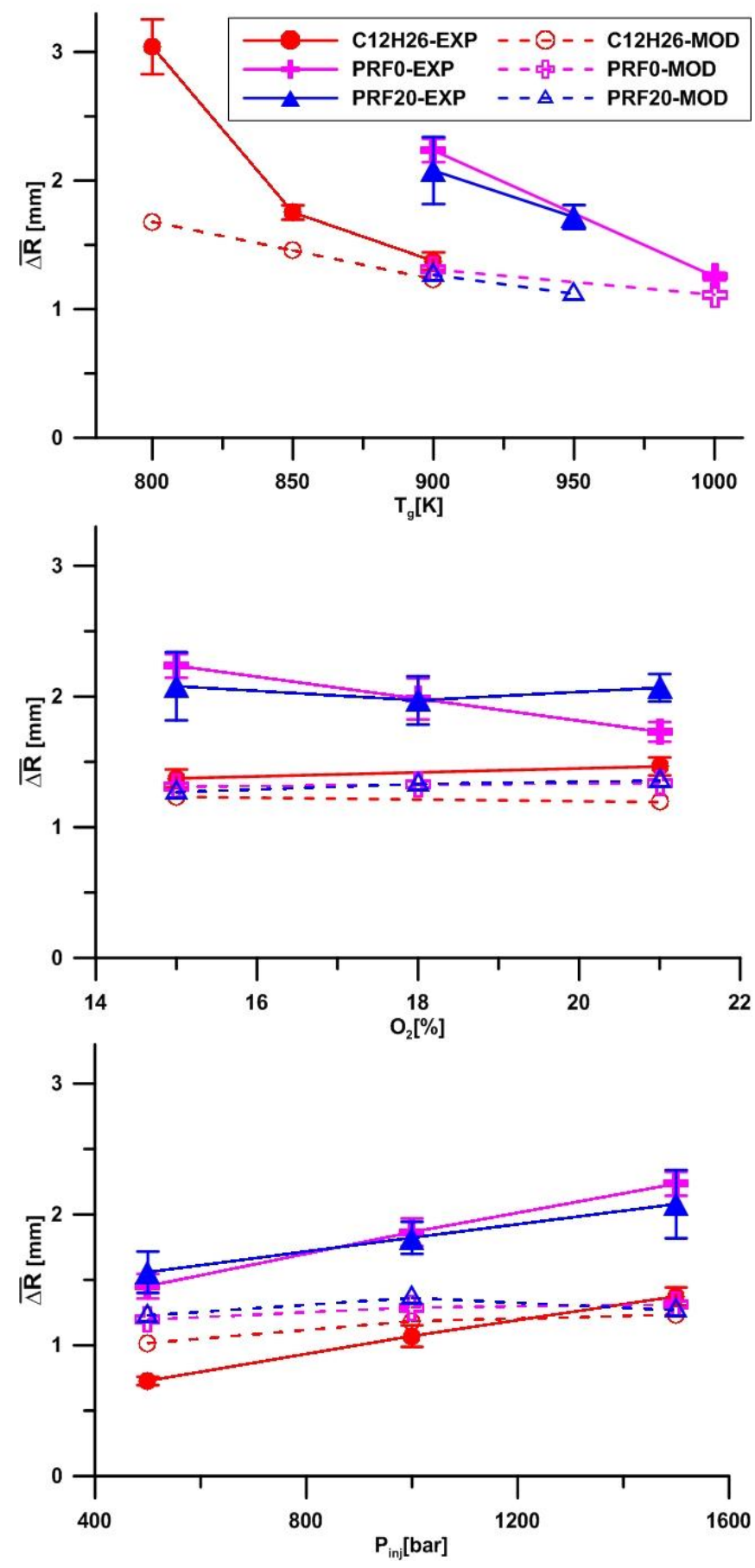

Figure $14-\overline{\Delta R}$ variation with ambient gas temperature (top), oxygen concentration (middle) and injection pressure (bottom). All variations are made based upon a nominal Spray A case, $\mathrm{Tg}=900 \mathrm{~K}, \mathrm{O}_{2} \%=15 \%$, Pinj $=1500 \mathrm{bar}$. Solid lines represent experimental results, while the dashed lines represent modelling results. 
Figure 14 (top) presents the effects of ambient gas temperature on $\overline{\Delta \mathrm{R}}$. For all three fuels, $\overline{\Delta \mathrm{R}}$ decreases with higher ambient temperature. In general, the scattering of measured values decreases with increasing ambient gas temperature, which means the flame structure is more repeatable within a higher temperature environment. In terms of modelling, one can observe a similar trend, with smaller radial dilation as temperature increases. Following the discussion in Section 3 and Appendix A, there are two factors influencing the radial expansion when temperature is decreased:

- The higher the ambient temperature, the closer to the nozzle the burning mixture is located (shorter $t_{\text {soc }}$ and $\mathrm{LOL}$ ), which should decrease the ready-to-burn mixture radius and consequently $\overline{\Delta \mathrm{R}}$, as from Eq. 7 .

- Figure 12 has shown the local inert to reacting density ratio as a function of mixture fraction for three different temperature values and PRFO. This parameter is seen to decrease with higher temperature, which would justify a reduced lateral expansion when moving from inert to reacting conditions.

Both effects would result in the same trend, namely an increase in radial expansion, which agrees with both experimental and numerical results in Figure 14.

The effect of ambient oxygen concentration on $\overline{\Delta \mathrm{R}}$ is shown in Figure 14 (middle), with no meaningful influence observed in neither experiments nor modelling results. According to the description in Section 3, the density drop and the location of the ready-to-burn mixture can explain $\overline{\Delta \mathrm{R}}$ results. Figure 11 has shown the local reacting to inert density ratio as a function of mixture fraction for the three oxygen values within the study. In the lean range (from the local minimum in density towards lower mixture fraction values) the local density drop is independent of oxygen concentration, while differences in the rich side are not too large. This fact confirms that the density drop will not change much with oxygen concentration. On the other hand, an increase in the oxygen content from 15 to $21 \%$ reduces ignition delay in $100 \mu \mathrm{s}$, as well as lift-off length in $5 \mathrm{~mm}$, which locates the ready-to-burn mixture on average around $4 \mathrm{~mm}$ closer to the nozzle. When considering both effects, it is the constant inert-to-reacting density drop which explains the similar radial expansion for all three oxygen cases.

The influence of injection pressure on $\overline{\Delta R}$ is shown in Figure 14 (bottom). It can be seen that $\overline{\Delta R}$ shows a slight increase with increasing injection pressure. All fuels show a similar sensitivity with injection pressure under such operating conditions, which is consistent with previous finding. Modelling results tend to increase from 500 to 1000 bar, becoming flat in the 1000 to 1500 bar range. In a first order of magnitude, injection pressure should have no effect on the local density, as already discussed in section 5.2. In global terms, the effect of injection pressure is just shifting the burning zone geometry by acting upon the lift-off length and the maximum extent of the spray. The higher the injection pressure, the further away from the nozzle combustion will occur, and according to the description in Section 3 this should result in a larger radial expansion, as experiments suggest.

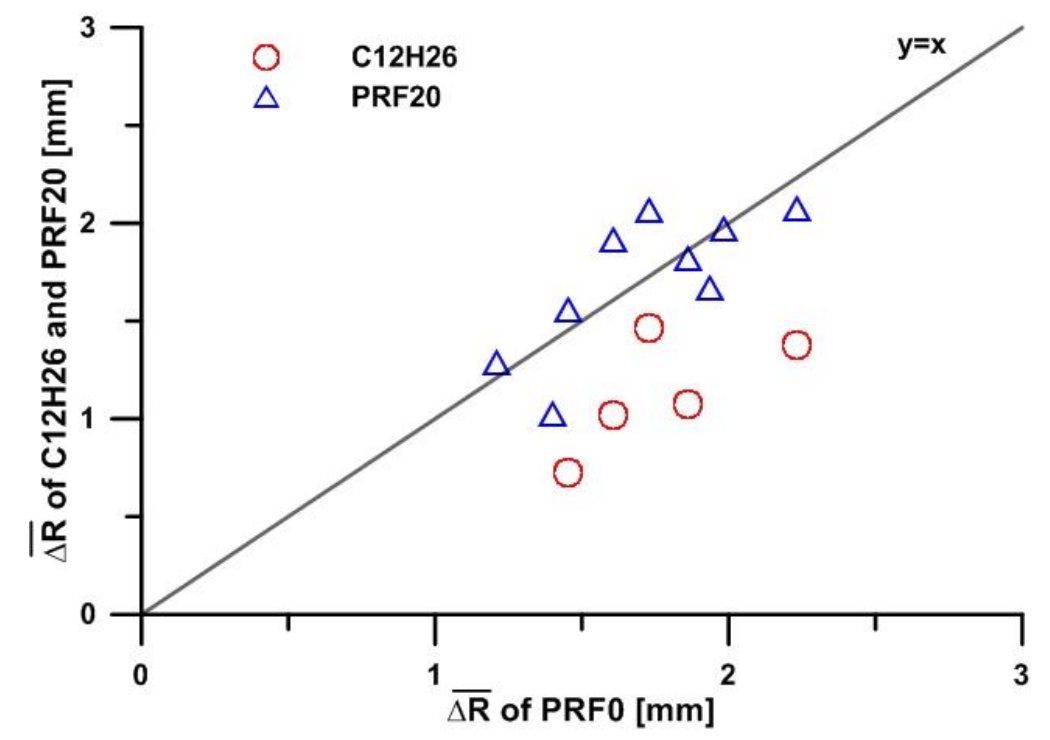

Figure 15 - Analysis of fuel effects on on average $\overline{\Delta R}$ 
Experimental values of $\overline{\Delta \mathrm{R}}$ are shown in Figure 15 from the fuel perspective. Each point compares the radial expansion of two fuels at identical operating conditions. PRFO, which has an intermediate cetane number, has been used as a reference. In general terms, trends among fuels are proportional, i.e. conditions with large or small expansion values are the same for all three fuels. PRF0 and PRF20 are closer to each other, while $\overline{\Delta R}$ of $n$-dodecane shows smaller values than that of other two fuels, which can also be found from modelling results. It must be noted that the higher cetane number of $n$-dodecane will result in a shorter ignition delay and lift-off length for the same operating conditions. This will bring ready-to-burn mixture closer to the nozzle, which will result in lower radial expansion.

Finally, previous plots have shown that the radial expansion predicted by the 1D model is always smaller in magnitude than that observed in the experiments. However, there is a proportionality between the model results and experiments, meaning that the model seems to capture experimental trends although with a lower sensitivity. The differences can be explained on the base of two arguments:

- First, one has to consider that the definitions of radial increase are different. Experimental results are based upon a 'median' location of the spray radial limit, while in case of modelling the radius corresponds to a more classical definition, namely the location where axial velocity is $1 \%$ of the on-axis velocity. Recent comparisons [22]0 between the present results and experimental local velocity results also indicate that the values of the second approach are smaller than those in the first one, in agreement with the modelling results shown here. In spite of that, model predictions of the velocity field within the spray for three investigated conditions are quite accurate compared to PIV experiments [22].

- Another point to consider is that, in the simplified description from the 1D model, the radial expansion is evaluated at start of combustion. Although this parameter does not change largely in time, temporal evolution [18] shows that the initial values are below the quasi-steady ones. This might mean that in reality the radial expansion process extends towards later timings after combustion onset, which brings the mixture further away from the nozzle and should therefore result in larger expansion values compared to the model.

\section{SUMMARY AND CONCLUSIONS}

In this paper, reacting diesel dynamics with different fuels has been studied by means of high-speed schlieren results and a 1D spray model. Reacting tip velocity and averaged spray radial increase $(\overline{\Delta R})$ during the quasi-steady phase of spray penetration were used as characteristic parameters for analysis. Some of the most important conclusions are summarized below.

1) A scaling factor ( $k$ ) based upon the time derivative of spray tip penetration has been defined to quantify the combustion-induced effect on spray tip velocity along the quasi-steady phase. A theoretical derivation of this parameter, which is accurately followed by inert spray cases, shows that it depends on momentum flux $\dot{M}_{0}$, air density $\rho_{a}$ and spreading angle.

2) Tip velocity values under reacting conditions are always larger than under inert ones, for both experimental and 1D model results. Parametric studies indicate that quasi-steady tip penetration velocity under the investigated conditions is not sensitive to ambient temperature, oxygen content or fuel cetane number. This has been explained in terms of the similar combustion-induced density drop due to similar fuel thermochemistry properties. Tip velocity scales with injection pressure, but with a similar trend as for the inert case.

3) Analysis of additional cases with similar ignition delay and lift-off length hint at the fact that reactivity of the mixture, which is controlled by chemical effects (cetane number, oxygen content or ambient temperature), has an effect on the transition timing from inert to reacting states, as well as on the initial penetration stages, but not on the quasi-steady phase.

4) Radial expansion results show similar trends with parametric variations for different fuels. It increases with lower ambient temperature and higher injection pressure, while it is insensitive to oxygen content. A simplified description indicates that this parameter is governed by density drop due to combustion and axial location of the ready-to-burn mixture at combustion onset. 
5) 1D model results show an underestimation of both tip velocity and radial expansion, mainly due to limitations in the simplified spray head approach. Trends are similar to experiments with a reduced sensitivity. Still, the model provides a good background for the explanation of experimental results, and for a first order of magnitude analysis of combustion effects upon spray development.

\section{ACKNOWLEDGEMENTS}

This study was partially funded by the Spanish Ministry of Economy and Competitiveness in the frame of the COMEFF (TRA2014-59483-R) project. Funding for Tiemin Xuan's PhD studies was granted by Universitat Politècnica de València thorugh the Programa de Apoyo para la Investigación y Desarrollo (PAID) (Grant reference FPI-2015-S21068).

\section{REFERENCES}

[1] John E. Dec, A Conceptual Model of DI Diesel Combustion Based on Laser-Sheet Imaging, SAE Technical Paper, $970873(1997)$

[2] M. P. B. Musculus, P.C. Miles, L. M. Pickett, Conceptual models for partially premixed low-temperature Diesel combustion, Progress in Energy and Combustion Science, 39 (2013) 246-283

[3] D. Hampai, L. Marchitto, S. B. Dabagov, L. Allocca, S. Alfuso, L. Innocenti, Desktop X-ray tomography for low contrast samples. Nuclear Instruments and Methods in Physics Research Section B: Beam Interactions with Materials and Atoms 309 (2013) 264-267

[4] S. Bhattacharjee, D. C. Haworth, Simulations of transient $n$-heptane and $n$-dodecane spray flames under enginerelevant conditions using a transported PDF method, Combustion and Flame, 160:10 (2013) 2083-2102

[5] F. J. Salvador, J. Martínez-López, J. V. Romero, M. D. Roselló, Influence of biofuels on the internal flow in Diesel injector nozzles, Mathematical and Computer Modeling 54 (2010) 1699-1705

[6] J. D. Naber, Dennis L. Siebers, Effects of Gas Density and Vaporization on Penetration and Dispersion of Diesel Sprays, SAE Technical Paper, 960034 (1996)

[7] I. V. Roisman, L. Araneo, C. Tropea, Effect of ambient pressure on penetration of a Diesel spray. International journal of multiphase flow, 33 (2007) 904-920

[8] F. Payri, R. Payri, M. Bardi, M. Carreres, Engine combustion network: Influence of the gas properties on the spray penetration and spreading angle. Experimental Thermal and Fluid Science, 53 (2014) 236-243

[9] M. P. B. Musculus, K. Kattke, Entrainment waves in Diesel jets, SAE Technical Paper, 2009-01-1355 (2009)

[10]S. Sasaki, H. Akagawa and K. Tsujimura, A Study on Surrounding Air Flow Induced by Diesel Sprays, SAE Technical Paper, 980805 (1998)

[11]Zhu, J., Kuti, O., and Nishida, K., Effects of Injection Pressure and Ambient Gas Density on Fuel - Ambient Gas Mixing and Combustion Characteristics of D.I. Diesel Spray, SAE Technical Paper 2011-01-1819, (2011)

[12]R.D. Reitz, F.V. Bracco, On the dependence of spray angle and other spray parameters on nozzle design and operating conditions, SAE Technical Paper 790494 (1979)

[13]H. Hiroyasu, M. Arai, Structures of fuel sprays in diesel engines, SAE Technical Paper 900475 (1990)

[14]M. Meijer, B. Somers, J. Johnson, J. Naber, S.-Y. Lee, L. M. Malbec, G. Bruneaux, L. M. Pickett, M. Bardi, R. Payri, T. Bazyn, Engine Combustion Network (ECN): Characterization and comparison of boundary conditions for different combustion vessels, Atomization and Sprays 22 (2012) 777-806 
[15]J.M. Desantes, J.V. Pastor, J.M. García-Oliver, F.J. Briceño, An experimental analysis on the evolution of the transient tip penetration in reacting diesel sprays, Combust. Flame 161 (2014) 2137-2150.

[16]C. Gong, M.Jangi, T. Lucchini, G. D’Errico, X.Bai, Large Eddy Simulation of Air Entrainment and Mixing in Reacting and Non-Reacting Diesel Sprays, Flow Turbulence Combust (2014) 93:385-404

[17]L. M. Pickett, S. Kook and T. C. Williams, Visualization of diesel spray penetration, cool-flame, ignition, hightemperature combustion, and soot formation using high-speed imaging, SAE Technical Paper 2009-01-0658, (2009)

[18]R. Payri, J. M. García-Oliver, T. Xuan, M. Bardi, A study on diesel spray tip penetration and radial expansion under reacting conditions, Applied Thermal Engineering 90 (2015) 619-629

[19]J.V. Pastor, J.M. García-Oliver, J.M. Pastor, W. Vera-Tudela, One-dimensional diesel spray modelling of multicomponent fuels, Atomization and Sprays, 25 (6): 485-517 (2015)

[20]J.V. Pastor, J.J. López, J.M. García, J.M. Pastor, A 1D Model for the Description of Mixing-Controlled Inert Diesel Sprays, Fuel, 87 (2008) 2871-2885

[21]J.V. Pastor, J.J. López, J.M. García, J.M. Pastor, A 1D Model for the Description of Mixing-Controlled Reacting Diesel Sprays, Combust. Flame 156 (2009) 234-249

[22]J.M. García-Oliver, L.M. Malbec, H. B. Toda, G. Bruneaux, A study on the interaction between local flow and flame structure for mixing-controlled diesel sprays, Combust. Flame, 179 (2017) 157-171

[23]Engine Combustion Network webpage: http://www.sandia.gov/ecn (online). Last access on May $15^{\text {th }} 2017$.

[24]R. Payri, J. M. García-Oliver, M. Bardi, J. Manin, Fuel temperature influence on Diesel sprays in inert and reacting conditions, Applied Thermal Engineering 35 (2012) 185-195

[25] G. S. Settles, Schlieren and shadowgraph techniques: visualizing phenomena in transparent media (Experimental Fluid Mechanic), Springer Verlag, Heidelberg, Germany, (2001)

[26]J. Benajes, R. Payri, M. Bardi, P. Martí-Aldaraví, Experimental characterization of Diesel ignition and lift-off length using a single-hole ECN injector, Applied thermal engineering 58 (2013) 554-563

[27]D. L. Siebers, B. Higgins, Flame Lift-Off on direct-injection Diesel sprays under quiescent conditions, SAE Technical Paper 2001-01-0530 (2001)

[28]D. L. Siebers, B. Higgins and Pickett, L., Flame Lift-Off on Direct-Injection Diesel Fuel Jets: Oxygen Concentration Effects, SAE Technical Paper 2002-01-0890 (2002)

[29]X. Tauzia, A. Maiboom, and G. Ma, A 1D Model for Diesel Sprays under Reacting Conditions, SAE Technical Paper 2015-24-2395 (2015)

[30]B. W. Knox and C. L. Genzale, Reduced-order numerical model for transient reacting diesel sprays with detailed kinetics, Int. J. Engine Res., 17 (2015) 261-279

[31]L. M. Pickett, J. Manin, C.L. Genzale, D.L. Siebers, M.P.B. Musculus, C.A. Idicheria, Relationship Between Diesel Fuel Spray Vapor Penetration/Dispersion and Local Fuel Mixture Fraction, SAE Int. J. Engines 4(1):764-799, 2011,

[32]F. Payri, V. Bermúdez, R. Payri, F.J. Salvador, The influence of cavitation on the internal flow and the spray characteristics in diesel injection nozzles, Fuel 83 (2004) 419-431 
[33]J.M. Desantes, R. Payri, F.J. Salvador, A. Gil, Development and validation of a theoretical model for diesel spray penetration, Fuel, 85 (2006) 910-917

[34]S. Kook, L.M. Pickett, Liquid length and vapor penetration of conventional, Fischer-Tropsch, coal-derived, and surrogate fuel sprays at high-temperature and high-pressure ambient conditions, Fuel 93 (2012) 539-548 


\section{APPENDIX A: Simplified expansion for a uniform density spray}

This section calculates the radial expansion induced by the inert-to-reacting transition for a spray flow under a simplified condition where the density throughout the spray is spatially uniform under both inert and also reacting conditions. Using Figure 4 as a reference, the model calculates the radial increase $\Delta R$ experience by a spray transiting in a zero time-step between the inert and reacting states at $t=t_{s o c}$. This means that density in Eq (1) can be moved out of the integrals,

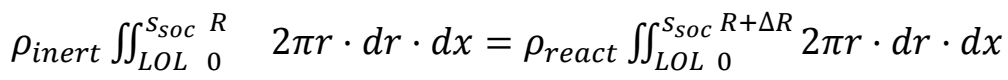

From which the integral terms only represent the volume that the ready-to-burn mixture occupies. Assuming that the inert spray is a cone, the volume integral reduces to:

$\iint_{L O L}^{s_{\text {SOC }} R} \quad 2 \pi r \cdot d r \cdot d x=\frac{\pi}{3} \tan ^{2}(\theta / 2)\left[s_{\text {SOC }}^{3}-L O L^{3}\right]$

And applying a similar procedure for the reacting spray, with a wider cross-section downstream of LOL the following result is obtained:

$\iint_{L O L 0}^{S_{S O C} R+\Delta R} 2 \pi r \cdot d r \cdot d x=\frac{\pi}{3} \tan ^{2}(\theta / 2)\left[\left(s_{S O C}+\frac{\Delta R}{\tan \left(\frac{\theta}{2}\right)}\right)^{3}-\left(L O L+\frac{\Delta R}{\tan \left(\frac{\theta}{2}\right)}\right)^{3}\right]$

By substituting into the original equation, the following analytical result for the radial expansion can be obtained:

$\Delta R=\tan \left(\frac{\theta}{2}\right) \cdot \frac{s_{S O C}+L O L}{2} \cdot\left[\sqrt{1-\left(1-\frac{\rho_{\text {inert }}}{\rho_{\text {react }}}\right) \cdot\left(\frac{2}{s_{S o c}+L O L}\right) \cdot \frac{2}{3} \cdot \frac{s_{S o c}^{3}-L O L^{3}}{s_{S o c}^{2}-L O L^{2}}}-1\right]$

The previous equation summarizes the main effects that govern the radial expansion:

- The density drop, as defined by $\frac{\rho_{\text {inert }}}{\rho_{\text {react }}}$

- The reacting volume geometry, as defined by the part of the cone from $\mathrm{x}=\mathrm{LOL}$ to $\mathrm{x}=S_{S o c}$. Two terms describe this effect:

- $R_{\text {avg }}=\tan \left(\frac{\theta}{2}\right) \cdot \frac{s_{S O C}+L O L}{2}$ corresponds to a radius at an average distance from the $\mathrm{x}=\mathrm{LOL}$ to $\mathrm{x}=S_{\text {Soc }}$.

○ The term $\frac{4}{3} \frac{S_{S O C}^{3}+L O L^{3}}{\left(s_{S O C}^{2}-L O L^{2}\right)\left(s_{S O C}+L O L\right)}$ which takes into account that the volume has a certain height in the axial direction. This term tends to unity if $s_{\text {soc }}-\mathrm{LOL}$ tends to zero, and increases with the distance between LOL and $\mathrm{s}_{\mathrm{soc}}$.

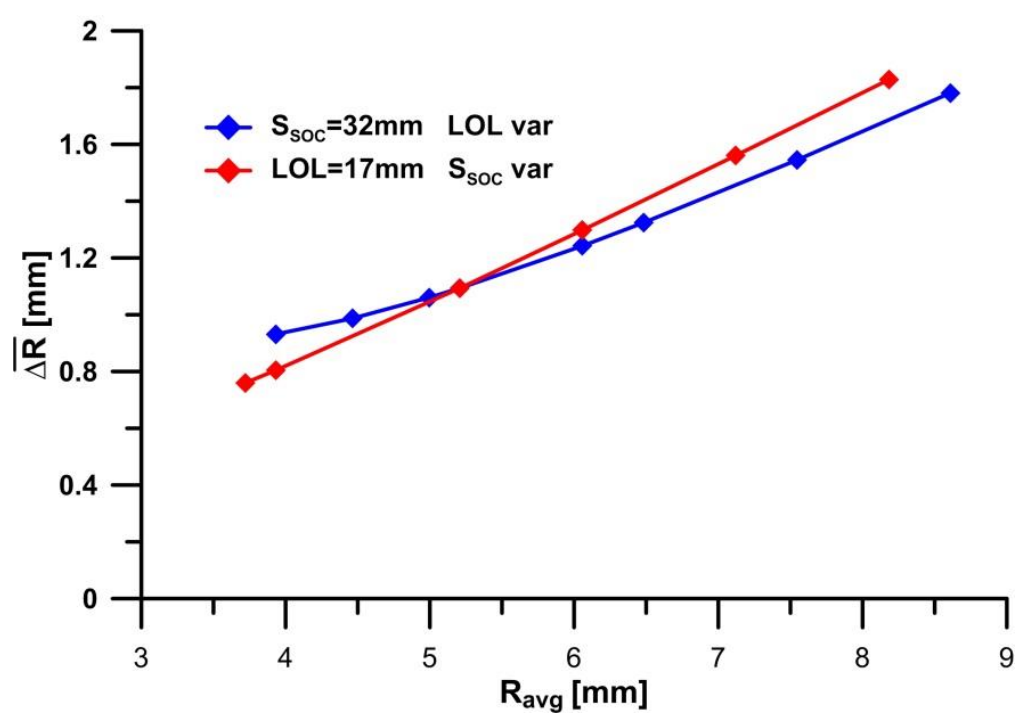

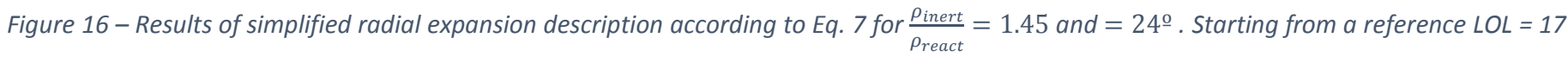
$\mathrm{mm}$ and $s_{\text {soc }}=32 \mathrm{~mm}$, an independent variation of both parameters is shown. 
Figure 16 shows results of the simplified model for a given density drop and inert spray cone angle for two independent variations of $s$ and LOL. Radial expansion is seen to depend on the geometry of the ready to burn mixture in terms of the average radius, i.e. in terms of $s_{\mathrm{soc}}$ and LOL. Increasing any of them means moving the readyto-burn mixture farther away from the nozzle, which always results in an increased radial expansion. The previous conclusions (and therefore Eq. 7) can be extended to non-uniform density distributions if the previously defined density values are assumed to be averaged values all over the spray volume. This means that increasing density drop or moving the ready-to-burn mixture away from the nozzle will increase radial expansion, as discussed in Section 5.3. 